\title{
Leibniz on Corporeal Substance
}

\author{
Peeter Müürsepp \\ Tallinn University of Technology \\ Akadeemia tee 3 , \\ Tallinn 12618, Estonia \\ E-mail: peeter.muursepp@ttu.ee
}

\begin{abstract}
As an idealist, Gottfried Wilhelm Leibniz could not recognize anything corporeal as substantial. However, under the influence of Cartesian terminology, he devoted considerable effort to analysing the corporeal world, while not recognizing its real substantiality of course. Leibniz took the concept of substance from Plato, Aristotle and the scholastics, but developed it in two ways. It is a well-known fact that Leibniz introduced the term 'corporeal substance' in his letter to Antoine Arnauld dated to October 1687. In the letter, Leibniz understands an object of nature, like an animal or a plant, as 'corporeal substance'. In the very same letter, Leibniz introduces the terms 'indivisibility' and 'phenomenon'. Every corporeal substance can be real only as a unity, i.e. by being indivisible. Such entity must have a soul or at least an entelechy. In an opposite case, that entity would not be a real unity but just a phenomenon. No corporeal entity is indivisible and therefore not a substance. The paper aims at introducing Leibniz's distinction between substances and phenomena and taking a closer look at the historicalphilosophical influences Leibniz experienced while developing his views of the corporeal world. Aristotle and Descartes will receive most of the attention, of course, as the concepts of 'entelechy' and 'hylomorphism' were introduced by the former, and the understanding of corporeal substance as determined by extension alone is part of the latter. The core of the original critique by Leibniz takes off from the properties of the continuum as well as the nature of shape, motion and extension. The case of continuum will receive special attention. It is analysed with the help of the novel approaches by Samuel Levey and Vassil Vidinsky. Leibniz was critical about our poor understanding of the continuum but his own interpretation of it was not fully consistent either. Although the new developments enable us to take a fresh look that has not been possible so far, the issue remains open for further study.
\end{abstract}


Key words: Aristotle, continuum, corporeal substance, Descartes, divisibility, entelechy, extension, hylomorphism, ontological levels, phenomenon, shape

\section{Introduction: Leibniz and the substances-phenomena distinction}

A number of books and papers have addressed the concept of substance. There is no need to dwell on these general considerations here, as anyone can look it up, for instance, in The Stanford Encyclopedia of Philosophy. Our focus is Leibniz and his understanding of the concept of substance and its role in understanding the world out there. Leibniz is normally included among the camp of Early Modern rationalists. The founder of the camp was René Descartes. Developing his cogito ergo sum, Descartes ended up recognizing two kinds of substances: the material one, the body, which is defined by extension, and the mental one, the mind, which is defined by thought. Principia Philosophiae contains a passage on the basic idea of corporeal substance: "Each substance has one principal property that constitutes its nature and essence, and to which all its other properties are referred. Thus extension in length, breadth, and depth constitutes the nature of corporeal substance" (Descartes, Principles I, 53).

Thus, the Cartesian understanding of corporeal substance is purely geometrical. This is the initial source of criticism by Leibniz. Descartes recognized the body as a physical entity. Therefore, a geometrical constitution cannot deliver all the concepts and properties that are important for a physical body. At best, geometry can be just part of the story. Other critics have referred to this issue as well.

Still, there are interesting points of the criticism in which Leibniz is original. We shall address these issues below. Most importantly, this concerns the role and understanding of the continuum. Leibniz makes a considerable contribution here but does not achieve full clarity either.

The paper aims at providing a historical background to the development of Leibniz's approach to corporeal substance with an emphasis on the Aristotelian influence. The latter may have had a more considerable impact on this part of Leibniz's philosophy than corresponding scholarship acknowledges so far. Still, the main argument of the paper concentrates on the above-mentioned original critique of the Cartesian approach to the body based on the treatment of the continuum. Several established scholars studying Leibniz, such as Daniel 
Garber, Paul Lodge and Pauline Phemister to name just a few, have addressed and thoroughly analysed the topic of corporeal substance in Leibniz. In the current paper, however, we focus on a couple of not so well known insights into the matter that are still highly innovative and open new possible pathways towards better understanding of the continuum and its connection to the issue of the shape and motion of bodies.

The number two rationalist, Spinoza, recognized just one substance that was both God and Nature. Obviously, Leibniz was aware of this approach and was influenced by both of his close predecessors. He was not particularly happy with either of these approaches, neither Descartes's nor Spinozàs. In the case of the latter, Leibniz did not like the idea that confined God to something that actually exists. For him, God must contain within himself all possibilities and not just the actual world. This view rules out the corporeal substance, at least partly. Still, Leibniz acknowledges created substances even though they are very closely dependent on God. He writes about this: "it is clear that created substances depend on God, who conserves them and indeed who produces them continuously by a kind of emanation, just as we produce our thoughts" (Leibniz, 1998, p. 66).

Our further analysis, however, rather takes off from Leibniz's interest in the Cartesian notions and approaches. Considering Leibniz's general idealist position, one would expect to see his negative or at least critical attitude to looking at the body as a substance. This is really the case. However, Leibniz dedicates quite an effort to analysing the essence of corporeality and its possible substantiality. The analysis is critical, of course, but not everything in this criticism is original. Several points that Leibniz has made are ones typical to an idealist approach. Still, there are important additions where Leibniz was original in his critique. These concern, for instance, the understanding of motion and extension in bodies. Still, motion and extension need not be anything substantial. They are just phenomena. This thought corresponds to the property of the continuum that enables subdivision into infinity. This is an issue which brings both space and time into the picture. "Leibniz's understanding of how movement relates to enduring states and how time is divided into moments will help to account for the continuum-based approach to these phenomena" (Müürsepp, 2011, p. 706). As the continuum subdivides into infinity, there can be no precise shapes of bodies. According to this rationale, an extended entity cannot be substantial but is just phenomenal. "The time continuum of infinite divisibility into moments works in the same direction supporting the Leibnizian claim of the nonsubstantial nature of any corporeal entity" (Müürsepp, 2011, p. 706). 
As we know, any substance must be, or at least contain, something that remains. These are the noumena, 'the things of the thought'. Phenomena, in contrast, are the things that appear for Leibniz (The Oxford Companion, 1995, p. 657).

Leibniz takes the understanding of substance from Plato, Aristotle and the scholastics. Influenced by Descartes and to a lesser extent by Spinoza, he develops the concept in two ways. The notion of the individual concept is crucial here. According to Hans Burkhardt (1993, p. 39), "[t]his concept is complete, i.e., every accident of the substance falls under a part concept of its individual concept; and it is also maximally consistent, i.e., it contains every concept consistent with it, and each additional concept would make it inconsistent". An individual concept explained like this can hardly be consistent with anything corporeal. Individual substance cannot have parts. However, the corporeal entity always has parts due to its Cartesian essence. Perhaps, the whole story could end here. Still, it would be interesting to take a closer look into the continuum-based interpretation proposed by Leibniz. That is exactly what we are going to do in more detail below.

In order to make sense of the understanding of substance by Leibniz we need to have a better grasp of his treatment of the notion of phenomenon. The common understanding is that there are different meanings of the term in Leibniz's writings. The first of those is quite typical of Leibniz's regular attitude. According to him, phenomena are simply illusions, nothing permanent. In that case, the perceptions of the conscious mind do not correspond to the objects of the external world. Leibniz has written a short but significant piece about this issue entitled 'On the Method of Distinguishing Real from Imaginary Phenomena' (GP, VII, pp. 319-322). Perhaps the main point that Leibniz is making in the essay is explaining that the imaginary or illusory phenomena are like dreams. Nothing real corresponds to them.

Leibniz elaborates on the topic in his famous letter to Arnauld. From this text, we learn that there are mental phenomena in addition to the imaginary ones. There is a typical example there, the rainbow. "In the case of the rainbow, the aggregate seems to be unified because the senses blur out the divisions between water droplets" (Burkhardt, 1993, p. 48). Leibniz, however, attributes the seeing of the colours to the senses themselves. He generalizes this position to all the secondary qualities.

The latter understanding connects the secondary qualities as phenomena to the bodily units, the senses. This is an important point against the substantiality 
of the body. The corporeal rather connects to the phenomenal than the substantial. It does not matter whether we remain with the Cartesian geometrical understanding of the body or add physical content to it.

\section{Substance and Entelechy, Leibniz and Aristotle}

It is a common knowledge among Leibniz scholars, and beyond, that Leibniz introduced the term 'corporeal substance' in one of his several letters to Arnauld, namely the one written in October 1687. The initial meaning of the term here is that of a living being in the most general terms, not just an animal but a plant as well. The mention of corporeal substance is closely connected to the Entelechies (capitalized by Leibniz). This connection is an interesting one. The Aristotelian term 'entelechy' is not equally important throughout Leibniz's writings as it appears in his later works. At first, Leibniz criticized the term, saying that Aristotle never gave a clear explanation, not to speak of a definition, of the term. Therefore, it is nothing that is applicable in the context of identifying of an object, being too vague for that purpose (GP, IV, p. 22).

An important and rather surprising change occurred quite soon, however. In his Discourse de Metaphysique, which Leibniz wrote barely one year before the 'crucial' letter to Arnauld, he suddenly takes quite a different stand concerning the Aristotelian notion. Now, Leibniz includes entelechy in the list of substantial forms, together with soul, calling them important for the understanding of the substance (Burkhardt, 1993, p. 43). Later on, 'entelechy' becomes more and more central for Leibniz. He even starts to differentiate between the first and second entelechies (entelechia prima and entelechia secunda). The idea behind this distinction is that the word 'entelechy' has different meanings. Among them is the interesting observation that "all souls are entelechies but not all entelechies are souls" (Burkhardt, 1993, p. 44). This is actually a later thought of Leibniz, expressed in Theodicy in 1710. Several observers think that this is not Aristotle's original position. Still, in De Anima, the Stagyrite presents a definition of the soul where he uses the term 'entelechy' as well as 'substance': "The soul must, then, be substance qua form of a natural body which has life potentially. Substance is actuality. The soul, therefore, will be the actuality of a body of this kind." (412a, pp. 19-21) As we see, the word 'entelechy' does not really appear in this particular quote. The issue is that 'entelechy' translates as 'actuality' here. This is a somewhat problematic thing to do. However, our main interest is 
not entelechy or actuality as such but rather their relationship to the substance, whether anything corporeal would come in. It appears that for Aristotle it hardly will. As the soul has to guarantee the actuality (entelechy) of the body, the latter is dependent on it and thus cannot be a real substance.

We have the key to understanding the two types of entelechies here. Entelechia prima is an active potentiality not realized and entelechia secunda is an active potentiality realized. There is the passive potentiality there as well. This would be the material world or, actually, matter itself. Thus, it is not surprising that Leibniz in his earlier works identified entelechy with force, effort or conatus (GP, VII, p. 588).

Leibniz says different things about entelechy and soul that are not always fully consistent, such as entelechy is analogous to a soul, it is similar to a soul or it is not identical to the soul. "There is only one soul in a living substance, the dominating monad, but there is an infinity of entelechies" (Burkhardt, 1993, p. 45).

For Aristotle, soul is the vehicle of the body. There is a normal causal connection between the two. It is just the same way as the general Aristotelian causality is holistic, connecting the material and formal sides of reality. Leibniz has a different solution. There is no causal connection between the soul and the body. 'Cooperation' of the two arranges the 'pre-established harmony'. This is part of common knowledge about Leibniz's philosophy. Quite often, however, we do not remember that the conception of pre-established harmony concerns the very core of Leibniz's metaphysics, his understanding of substances. Of course, the connection to monadology is always obvious.

There is the matter of perception here. In his crucial letter to Arnauld, Leibniz makes an interesting observation that there is no principal difference between natural perception and intellectual knowledge. According to Leibniz, they are actually both perception and the so-called natural perception and knowledge are just different "species" of perception. For a moment, Leibniz's monadology looks quite similar to material atomism here. Later on, Leibniz starts to call the conscious or reflexive perceptions 'apperceptions'. As a result, the atomistic image of the monads fades quickly away, giving way to the well-known Leibnizian characterization of representation of the whole world by every single monad. This leaves monads in the camp of the ideal entities. No material atoms, no bodily substance, one might claim. Probably rightly so. Somewhat unexpectedly, however, the story becomes more complicated here and it will be elaborated on 
in the next section. It appears that Aristotle had a lot more to say in the context of corporeal substance.

\section{Substances and substantiata (Aristotle still involved)}

The distinction between substances and substantiata in Leibniz appears in the context of mereology, the theory of the relationship between the part and the whole. There are integral wholes. These can be living things like human beings or artefacts like machines. This type of integral wholes Leibniz also calls substances. In the case of integral wholes, some parts are separable and some are not. In addition, there are still essential wholes and aggregates. In the case of the former, no part is separable, in the case of the latter, all parts are. The examples of essential wholes would be God, angel and soul, as well as geometrical entities.

How does this connect to the issue of substances? The aggregates, the kind of heap type of objects, Leibniz explains as a contingent set of individual substances. Here he includes corporeal substances into the list of possible substances together with monads (simple substances). He understands corporeal substances as compound ones, of course. The latter are the substantiata. There are actually two types of them: substantiata per se are the compound substances that have parts, substantiata per accidens are the aggregates or heaps that are nothing but the sum of their parts.

Is there a contradiction in Leibniz's understanding? Substances, including the corporeal ones, have to be essential wholes and as such are not divisible. However, on the other hand, they have both essential and non-essential parts that makes them divisible and not just divisible but even separable. By all evidence, Leibniz noticed the problem. He points it out in the commentary he made to an analysis of the issue by Jungius. Thus, we have to admit that Leibniz knew about the problem before he made his commentary. The issue has been addressed by Burkhardt and Degen (1990, p. 5) but it is obviously not a resolved question. Leibniz was inclined to show that the corporeal could not be a real substance. The monads were not corporeal but ideal units. Still, there was the Cartesian approach that gave the body an essential role comparable to the mental substance. This might be the foundation of the Leibnizian confusion, or at least hesitation about the issue. 
It is an interesting question whether the issue clarifies with the help of introducing the notions of 'dissective' and 'expansive'. The inventor of the 'grue' and 'bleen' problem, Nelson Goodman (1951), steps in here. The former are the properties that distribute from the whole to its parts. Still, these notions rather confuse than clarify the picture. It appears that the property "to be the best" is not dissective by the reason that even in the best of all possible worlds not every part is the best. Why is that so? Perhaps there could be a better part in a world which itself is not the best, but not necessarily so. In principle, the best of all the possible worlds should be the one in which every single part of any character is the very best one.

Still, there is the issue of the quantitative and the qualitative whole. The observation given at the end of the previous paragraph is true as far as the quantitative whole is concerned, but it is debatable whether we take the world to be a qualitative whole. It is rather the opinion that Leibniz was looking at the world as a qualitative whole. Definitely, our actual world was the best possible one for Leibniz. Does this not mean that it had to be the best possible one in both qualitative and quantitative sense? In the general case, the understanding perhaps should be like this but Leibniz may really be an exception here. Qualitative perfection might have been enough for him. 'Expansive' would mean being hereditary from the parts to the whole.

It remains an open question what Leibniz actually attempted to achieve with his distinction between substances and substatiata. A possible hypothesis would be that he tried to position the corporeal somewhat away from the real substantiality that has to be a whole but at the same time still give some credit to the bodily world as something important for the human existence. Again, it may have been the Cartesian influence.

This brings us to the interesting question whether Leibniz was a supporter of hylomorphism and if so, in which particular way. It is common knowledge in philosophy that hylomorphism was introduced by Aristotle for the purpose of explaining how form and matter interact with each other, penetrate each other and become inseparable. In the human being, soul and body represent form and matter. There is another piece of common philosophical knowledge that St. Thomas Aquinas was a follower of Aristotle in this issue. It is not that widely known, however, that St. Bonaventure has made his mark here as well. He was a contemporary of Aquinas and accepted the Aristotelian approach but he still viewed the relation between soul and body differently. Bonaventure's original idea was that the soul itself has a hylomorphic structure (Hayes, 1991, pp. 9496). Therefore, the soul must contain matter. 
Obviously, here too Leibniz was under the influence of Descartes's dualistic philosophy and could not agree with the Aristotelian-Thomistic approach. Rather, he accepted a hylomorphism of the soul close to the understanding of St. Bonaventure (Burkhardt, 1993, p. 52). In the case of Leibniz, however, it is rather about the monads than the soul itself. The monads do not have parts as we know. They have perceptions and apperceptions. The latter are the reflexive mental acts, the former the non-reflexive mental acts. Perceptions represent the body and apperceptions represent the mind.

It is true that Leibniz's understanding of the monads has a connection to hylomorphism. However, it is not the original Aristotelian approach to the topic. It is similar to Bonaventure's treatment of the matter. True, Aristotle invented hylomorphism with the purpose of addressing entities that do not have separable parts but at the same time do have distinguishable constituents. The same appears to be true about Leibniz's monads. Still, the topic of hylomorphism in the connection of corporeal substance remains an interesting thread, especially if we adhere to the approach of St. Bonaventure. The corporeal normally connects to the ontological, as discussed more closely below.

\section{Ontological levels—do they matter?}

There is an agreement, at least to some extent, among the Leibniz scholars that his texts reveal three ontological levels.

First, there are the monads. They do not have parts. Therefore, they are mereologically primitive.

Our main focus, compound corporeal substance, can be found at the second level. "Compound corporeal substances are integral wholes from which some parts are separable and some not" (Burkhardt, 1993, p. 52). There is nothing new to us in that. Still, let us consider what the third level has to offer.

The last level contains appearances of aggregates or of phenomena. Aggregates are heaps. Their parts are fully separable. There is no systematic organization. Unity of the aggregates is either illusory or perceptual/conceptual (Brown, 1990, p. 21).

Our perspective gives rise to a rather interesting question — namely, do the heaps or their composite parts have any relation to corporeal substantiality? The heaps 
could hardly have any, as they are nothing in their own right. They are just composites of objects. Thus, they cannot be substantial either. There composite parts seem to be perfect bodies if on their own. They are integral wholes. Do they have separable parts and do they have not separable ones is a good question and one that is not so easy to answer. The main issue here is the problem of the parts that are not separable. In principle, any corporeal entities can form heaps. However, this is not how nature works and how the humans act. We do not heap together just anything. Still, entities from the third ontological level could be included in the role of corporeal substances but not the heaps as such but the composite parts of them. On the other hand, the composite parts are bodies in their own right. Therefore, it is the case that the third ontological level does not add anything to the issue of corporeal substances. The second level is enough. After all, the heaps do not expose anything new to us. They are compounds of bodies that are bodies in their own right.

The ontological status of matter has been weak throughout the history of philosophy. Matter was something secondary for Plato. Aristotle is supposed to have turned the tables but even for him it is still rather the formal part of the entity making it what it is wise in terms of species, although not in the case of the individual. "Despite the hylomorphic structure, substance for Aristotle is characterized by properties coming from its form or soul, such as its activity, its indivisibility, its unity, and its finality" (Burkhardt, 1993, p. 52). True, Aristotle managed to elaborate his understanding of the hylomorphic doctrine. His prime matter is a pure rational entity without any empirical counterpart. His secondary matter, however, has a form or entelechy and can be part of an empirical entity. Empirical material reality steps in here.

The Aristotelian approach was clearly different from the Cartesian one. Leibniz was in opposition with the latter but was strongly influenced by it, especially as far as the terminology is concerned. It is difficult to prove that but Leibniz seems to have tried to combine the Cartesian approach with the Aristotelian one. On the one hand, he takes over the Cartesian dualistic position in the sense that there is no causal relation between soul and body but only a pre-established harmony between them. On the other hand, in his mature years, Leibniz reactivated the basic Aristotelian metaphysical concepts like materia prima, materia secunda, entelechia prima, and entelechia secunda (Burkhardt, 1993, p. 53). Burkhardt even claims that Leibniz constructed a metaphysical system, which appears to be a synthesis of Platonism, Aristotelianism and Cartesianism (Burkhardt, 1993, p. 53). However, any metaphysical system probably has to contain elements from 
Plato, Aristotle and Descartes in order to be metaphysical at all and to create a connection with the preceding systems. If anyone decides to construct something new in metaphysics, what are the options? Plato, Aristotle and Descartes are almost inevitably present for her. Some connection with at least some of them has to be established. After all, considering all the innovative moments in Leibniz's metaphysics, one obviously cannot give an exhaustive account of it just by basing it on Plato, Aristotle and Descartes.

In conclusion, we have to admit that the ontological levels do not matter too much concerning understanding the issue of corporeal substance. However, addressing the levels enables us to understand better the connections of Leibniz's metaphysics with that of his influential predecessors, most notably Aristotle and Descartes. In addition, the position of the compound body in the ontological system still places the issue of corporeal substance into clearer focus. The observation concerning the distinction between the compound bodies and aggregates or heaps is an interesting one as well.

\section{Leibniz as an original critic of the geometrical approach}

As mentioned above, several critics have pointed out that an approach based on the geometrical idea of extension cannot grasp the essence of the bodily substance because the latter is something physical (material). Leibniz, however, has gone further and analysed in detail the concepts used by Descartes.

Leibniz points out that notions involved in extension are not clear and contain something imaginary in the sense that the purely geometrical understanding of the extension cannot involve actual bodies. The Cartesian attribute of extension can apply only to our own imagination, not to anything outside of our mentality. Leibniz has noted this in several texts, mostly in the 1680s. There is even a text with a very indicative title, Wonders Concerning the Nature of Corporeal Substance (Leibniz, 1683). Leibniz emphasizes that neither extension nor motion are conceptions that we understand distinctly enough. Here is the link to the interesting problems concerning the infinite and the continuum we definitely need to address in further detail. Another problem is that there are no precise shapes in the nature of things as well as there are no precise motions. For this reason, Leibniz calls extension and motion just phenomena, such as, for instance, 
colour or sound. Neither of these are true attributes of things and thus not good enough to form the basis for anything substantial.

Another important text by Leibniz from the same thread is A Specimen of Discoveries of the Admirable Secrets of Nature in General (Leibniz, 1686). Here Leibniz brings forth the argument of divisibility. It goes as follows. There is no body so small that it is not possible to divide it into even smaller parts. This observation is more important than it actually seems to be. It means that no definite shape can be assigned to any body, just like nothing geometrical (line, circle, etc.) is assignable to the shape of any body that one can find in nature. This is the reason why Leibniz says that the conception of extension involves something imaginary. Again, Leibniz blames us (perhaps including himself) for the poor understanding of the composition of the continuum.

Curiously, this argument involving a very interesting reference to the essence of the continuum has attracted so little attention from Leibniz scholars over the years. Still, several authors (Adams, 1994; Beeley, 1999; Levey, 2005; etc.) seem to be familiar with the argument but from different writings of Leibniz. Obviously, there are slightly different ways how Leibniz himself has presented the argument in different texts. We cannot analyse all of them here. The version by Samuel Levey is perhaps one of the most simple and straightforward ones for our point of departure. Levey has established the argument cumulatively into three points, where each successive one builds on the former:

1) "There are no precise shapes in actual bodies, because of the subdivision of the continuum to infinity.

2) The notions of shape, motion, and extension are not in things outside us but rather are only imaginary, like those of colour, heat, and sound.

3) Shape, motion, and extension are not qualities that can constitute substance." (Levey, 2010, p. 149)

The understanding of the continuum is clearly the focus of the problem. Leibniz seems to think that the subdivision of the continuum to infinity is responsible for the bodies not having precise shapes. Let us take a closer look.

Leibniz has two arguments here. The first, the clearly primary one, appears in many texts. The argument rests on Leibniz's understanding of the material universe as a vessel full of liquid that rests on his theory of the ether. As in a pond of water, the movement of some body will always propagate so that there is impact on every other body. This creates the situation where every body is 
all the time subjected to an infinity of impulses. For Leibniz, this observation suggests that "there is no body so small that it is not actually subdivided" (GP VI, p. 4, 1647).

There are two important observations on this position. First, Leibniz is critical of Descartes's conception of corporeal substance because of the purely geometrical explanation based on the notion of extension. Here, Leibniz's own criticism seems to be based on geometrical thinking as well. Still, we know that in the late 1670s Leibniz rejected the idea of rigid atoms in favour of elasticity in physical bodies. It seems as if Leibniz was interested in keeping the geometrical approach based on the rigidity of bodies but had to abandon it after realizing its limitations. There was no topology around in those days. Just Descartes's and Leibniz's own sophisticated but still classical geometry. This geometry focused very much on divisibility. Let us remember the infinitesimal calculus here. In this method, the shape is directly dependent on division, on the measure of divisibility.

The shape that is based on divisibility cannot be a precise shape in principle. This is an important part of the argument for the 'No Perfect Shape'. It is empirically evident that there cannot be perfect shapes in nature. However, a geometrical explanation is possible as well. Still, Leibniz's position is not clear here. He speaks about a straight line and two points $\mathrm{A}$ and $\mathrm{B}$, the line being between them, but also takes these two points as parts of the line. These two notions are not necessarily equivalent. This indicates that Leibniz himself was not consistent in his understanding of the continuum throughout his publications.

There are still good reasons to agree with the common understanding of the argument of the 'No Perfect Shape'. Leibniz argued that

Since the different parts of any line, however small, could be uniform and undivided, as the 'exact' straight lines of traditional geometry are imagined to be. Actual lines - such as the edges of bodies or the paths carved out by the vertices of moving objects-must instead be divided into distinct parts that in fact deviate from one another in their directions, however subtly, and thus at best can only appear to form a single exactly straight line. (Levey, 2010, p. 152)

This result extends from the lines to the bodies. We find that there is no body that can be indivisible, even though under some circumstances some may appear 
as such. This result works in clear favour of not considering anything bodily to be a substance.

It may be that Leibniz was looking for a way out of the geometrical interpretation of the continuum, for a way to bring the idea of the continuum into the physical world of bodies. The latter as substances should be indivisible but they are not. Some bodies may seem undivided wholes and there may be even quite strong topological support for the view but the extrapolation from the continuum yields a different result.

It is interesting to point out here that there is a dynamical interpretation of Leibniz's continuum. Vassil Vidinsky introduced the expression in his paper bearing the same title (Vidinsky, 2008). The author elaborates on the traditional (for Leibniz scholars) Rescher's split between the monads (the real world presented by metaphysics) and things (the phenomenal world presented by sciences). Nicholas Rescher was actually the author who pointed out such split, emphasizing that it is the phenomenal world that forms the object of the sciences, first of all physics, the science proper (Rescher, 1979, p. 65).

Later on, suggestions to advance Rescher's split into two started to appear. For instance, Hartz and Cover (1988) have argued that a division into three would be in better accord with Leibniz's views. They distinguish between the monads that have full and non-derivative reality, bodies that are grounded on monads and therefore not real but phenomenal, and abstract entities like space and time that are ideal things (Hartz \& Cover, 1988).

According to such an interpretation, the body cannot be a substance. Hartz and Cover (1988, pp. 503-504) call monads substantial, bodies quasi-substantial and the ideal things res mentalis. The contribution of Vassil Vidinsky starts here. He maps the Law of Continuity on the threefold structure.

Let us remember that our current interest is the continuum rather than continuity as such if there is any difference. Below, we shall take a closer look with the help of Vidinsky and the classical authors, including Leibniz himself. First, there is the famous dictum of Leibniz that nature never makes leaps. The first articulation of this view probably appears in Leibniz's letter to de Volder from 3 April 1699. More famously, however, it appears in Die Philosophischen Schriften (GP, II, p. 168), where it reads: "Nothing takes place suddenly, and it is one of my great and best confirmed axioms that nature never makes leaps. I call this the Law of Continuity". Just six years later, on 11 October 1705, Leibniz 
writes to de Volder again, saying that: "Matter is not continuous but discrete, and actually infinitely divided” (GP, II, p. 278).

Do we have a major contradiction here? Some people, like Bertrand Russell, see it that way: "In spite of the law of continuity, Leibniz's philosophy may be described as a complete denial of the continuous" (Russell, 1900, p. 111). Still, a quite different interpretation of the issue is possible. It is just the infinite divisibility of material bodies that makes the world continuous for Leibniz and does not accept any leaps.

There is an interesting conception of syncategorematic infinity by Richard Arthur, who explains:

All naturally occurring transitions are continuous in that the difference between neighboring states is smaller than any assignable. This means not that there exists a smaller one. Thus there is a true continuous transition, even though the states themselves and all assignable differences between them are actually discrete. (Arthur, 2007)

Still, this is not completely satisfying. How to understand that there does not exist or at least necessarily does not exist a smaller difference between the assignable differences? Is not it all just about the infinite divisibility? This is what makes the Law of Continuity work. There is always a smaller difference available. Richard Arthur is right in that we need not see Leibniz's own position and Russell's interpretation as contradicting each other. But his explanation of the issue is not completely satisfying. It seems that Arthur misses the main point. The whole idea of the calculus rests on this idea. There has to be a 'jump over the infinite'. As the jump occurs over the infinite, it is not a real jump but rather a license for continuity. Leibniz's view of the material world is kind of a dialectical unity of continuity and discreteness. Paradoxically enough, both interpretations of Leibniz's understanding of the corporeal could be correct:

1) The Law of Continuity holds, there are no leaps in nature, there is always a smaller unit between two ones;

2) The nature is discrete, there is no continuity whatsoever (the Russellian approach).

How to resolve the issue? If we necessarily need to come up with a solution then we should perhaps respect what Leibniz himself had to say. His clear position was-no leaps. If we can respect that then there is no need to pay serious attention to what Russell had to say. However, it is not as simple as that. Leibniz 
did not recognize the corporeal as a real substance. The main reason for this seems to be the infinite divisibility of the body, any body, however small. On the other hand, the Law of Continuity is supposed to hold. Therefore, the bodies should be continuous wholes. Why not substances then? Perhaps, the so-called clear understanding of the continuum can provide us with an answer if not with a solution.

\section{Different types of the continuum—how do they matter?}

Continuum connects to infinity. It is no news that there are different types of infinity. Leibniz raises the issue in a somewhat puzzling way: "infinity, that is to say the accumulation of an infinite number of substances, is, properly speaking, not a whole any more than infinite number itself, whereof one cannot say whether it is even or uneven" (GP, VI, p. 232). If so, then there is no such thing as an infinite number because a number is always even or odd. However, do we need an infinite number as such? There are infinitely many numbers and this is it.

This case is interesting because it illustrates the difference between the approach of Arthur and Russell, that is, between infinite division and actual division. How does this relate to the continuum, though?

Leibniz obviously holds that the phenomenal world is discrete but this is not the 'classical' discreteness. Leibniz's discreteness means that there is always something between any two states.

Vassil Vidinsky (2008) makes an excellent suggestion here. We have to make a clear distinction between the ontological and epistemological approaches. We are on the ontological ground when we are dealing with the question of corporeal substance. In order to be a substance, the corporeal has to exist and in order to be corporeal it has to exist as a body. However, Leibniz's understanding of the infinite divisibility is not ontological. It is rather epistemological. From the point of view of natural science, it would be tempting to say that one interpretation, the ontological one, is real and the other one is an ideal one. Here we have the basis for two types of continuums, the ideal and the real one. It is not clear, however, where is the real and where is the ideal continuum. If we stick to the traditional mathematical (geometrical) interpretation then that would be the real continuum. In the phenomenal world, we would be having rather continuity than continuum as such. But if there is infinite divisibility then there are big 
problems with continuity. The continuum in the phenomenal world is not the real one. Therefore, we cannot resolve the issue of corporeal substance with the help of the continuum hypothesis. Or is this conclusion premature?

After all, if we deny the reality of the continuum in the phenomenal world then the latter has to be continuous and the Law of Continuity holds. This would be a real continuity. However, this is probably not in accord with Leibniz's position. For Leibniz, the phenomenal world is discrete in its continuity. This is possible exactly because the material world is phenomenal for Leibniz. It is not real. The monads are real. Therefore, there can be inconsistencies in the epistemology of the phenomenal world.

What about the dynamical interpretation of the continuum now? This interpretation is needed and possible in the phenomenal world only. Thus, the dynamical continuum is not the real one. It is an adaptation of the mathematical concept to the real world. It has the same kind of problems as in the case of any other mathematical (especially geometrical) application of mathematics to the corporeal world. Two stones are really and exactly two stones. But there is no sphere or cylinder, not to speak of circle in the material world. However, approximations are possible and sometimes useful. The same holds true for the continuum. The hypothesis works in mathematics. There it is real. In the phenomenal world, we can use the concept just as an approximate explanation or model that will never exactly correspond to the material reality. According to Phemister, Leibniz acknowledged the difference: "The source of the problem of the composition of the continuum, Leibniz advises, is found in our tendency to confuse the mathematical ideal with what is true of the physical world" (Phemister, 2005, p. 105).

It seems that we have managed to make sense of the two understandings of the continuum. But what is the significance of this observation to the problem of corporeal substance? We have more ground in stating that if we consider adherence to the continuum important then we have given more solid ground to the statement that the corporeal is not real in the sense of qualifying as a substance. We have to keep in mind, however, that this statement depends on the realm of mathematics. Compared to the mathematical reality, the corporeal reality is quite different. It reveals itself only to sense perception. We know that since the ancient times already. What did Zeno really try to say with his paradoxes? He was hardly thinking in terms of the continuum but, in principle, he discovered the mathematical (logical) continuum and tried to connect (or disconnect?) it to the world of senses. Since then preference in scientific research has been with reason 
rather than with the senses. Mathematical reality obtained an especially highly valued status. The powerful shadow of the Eleatics (Parmenides and Zeno), propagated throughout the Occident, by all evidence reached Leibniz. Descartes managed to bring the corporeal into the focus of our interaction with the world. Leibniz relied mostly on reason again.

Still, why did Leibniz claim that the Cartesian theory of the body, that is, calling it a substance, rests on a poor understanding of the composition of the continuum? For Descartes, the shape, extension, was everything a body needed to be a body. According to Leibniz, there is no perfect shape. More than that, the very notion of shape cannot accurately describe anything, as it is an abstract notion. "The Cartesian theory of body cannot offer an account of the true nature of actual bodies as they are in themselves; and thus it collapses as a metaphysics of corporeal substance" (Levey, 2010, p. 167).

Actually, Samuel Levey goes further as he claims that "Leibniz’s considerations about the notion of an enduring state will have far more profound consequences than just the defeat of the Cartesian conception of body" (Levey, 2010, p. 168). Levey makes a very reasonable distinction. There is the primary argument, the geometrical one, which says that there are no precise shapes in things because assignable shapes are geometrical in the classical sense but the boundaries of the real bodies have the fractal structure. In addition, there is the secondary argument, according to which shape must be enduring but time is fractally divided (Levey, 2010, p. 168). Thus, Leibniz has addressed and actually refuted the Cartesian account of the body from both crucial angles. He successfully challenged the idea of precise shapes in things and the idea of enduring states. "Not only will no body that is defined in terms of magnitude, shape, and motion be truly substantial, but also nothing that is supposed to have either momentary or enduring states will ever be more than imaginary" (Levey, 2010, p. 169).

Bringing in fractal geometry may seem a challenging move. There is a temptation to discard it altogether as a too adventurous one. Before doing so, however, it would be interesting to take a deeper look into this highly innovative idea. After all, the idea of self-similarity of a curve is also Leibnizian and has been recognized as such by Benoit Mandelbrot (1977, p. 419) himself: "I have diverse definitions for the straight line. The straight line is a curve, any part of which is similar to the whole, and it alone has this property, not only among curves but among sets.' This claim can be proved today." Still, developing this thread will remain a task for forthcoming papers. 


\section{Conclusion}

The topic of Leibniz's critique of corporeal substance is an integral part of his philosophy. It connects closely to the core of it, monadology. Quite obviously, the conception of the monad, although an ideal entity, took its final shape for Leibniz under considerable influence of both Cartesian substances.

The initiators of Modern philosophy turned a new page in the development of the discipline. There is no reasonable doubt about this. However, the most visible pages that appeared before had a great impact on them. Leibniz is not an exception. He took his initial understanding of the conception of the substance from Plato and Aristotle. It is the latter, however, whose writings about the connection of the material and the formal, the body and the soul that ripened into the conception of hylomorphism and the considerations of the entelechy, that are most important to Leibniz in his understanding of the bodily substance. It was interesting to observe that Leibniz's position concerning hylomorphism appears to be closer to St. Bonaventure's rather than to the original Aristotelian or the well-known Thomist ones.

Obviously, accepting the corporeal as a substance does not fit into Leibniz's understanding of how our world functions, at least not in the later period of his philosophy. Therefore, he had to keep looking for sound arguments that would undermine the Cartesian understanding of the body. As Descartes defined the body by extension alone, not adding anything physical into its essence, attacking this omission could be a reasonable choice. Leibniz, however, decided to challenge his opponent with his own weapons taken from geometry. There is nothing new in saying that Leibniz's original criticism of the substantiality of the body stemmed from a poor understanding of the continuum. At the same time, Leibniz himself did not show full consistency concerning this issue either. Here, further clarification would still be necessary.

The current paper provides additional grounds to the idea that studying the continuum, in terms of how Leibniz understood and interpreted it and why he referred to the misunderstanding in this matter, can shed new light to the issue of corporeal substance as well. These grounds derive from the help of a few Leibniz scholars who do not occupy a central position in the community, at least not yet. Vassil Vidinsky has provided us with an interesting conception of the dynamical interpretation of the continuum. Samuel Levey, on his part, has introduced no less interesting idea of replacing the traditional notion of 
the geometrical shape with that of a fractal structure. Boundaries of bodies certainly accept the interpretation as fractal structures just like borders between countries or coastlines. Perhaps calling a body fractally divided is a very good way to approach this issue concerning the bodies, whereas time as a continuation definitely attests to it being regarded as fractally divided.

It may be that a proper understanding of the continuum could not be achievable in Leibniz's time. Perhaps it is beyond our reach even today despite the many interesting developments in geometry since the 18th century. Fractal geometry may have brought us closer to the solution but we do not know yet whether it is enough to provide what Leibniz was looking for. Therefore, it would be interesting and even necessary to keep looking.

\section{References}

Adams, R. (1994), Leibniz: Determinist, Theist, Idealist, New York: Oxford University Press.

Aristotle (1983), De Anima, translated with an introduction and notes by D.W. Hamlyn, Oxford: Oxford University Press.

Arthur, R. T. W. (2007), 'A complete denial of the continuous? Leibniz's Law of Continuity,' Synthese, vol. 36, pp. 325-351.

Beeley, P. (1999), 'Mathematics and nature in Leibniz's early metaphysics,' in S. Brown (ed.) The Young Leibniz and His Philosophy (1646-76). Dordrecht: Kluwer. https://doi.org/10.1007/978-94-017-3507-0_7

Brown, C. (1990), Leibniz and Strawson: a New Essay in Descriptive Metaphysics, Munich, Handen \& Vienna: Philosophia.

Burkhardt, H. (1993), 'Adam's mind and body,' in M. Dascal \& E. Yakira (eds.) Leibniz and Adam, Tel Aviv: University Publishing Projects Ltd., pp. 39-56.

Burkhardt, H. \& Degen, W. (1990), 'Mereology in Leibniz's logic and philosophy,' Topoi 9, pp. 2-13. https://doi.org/10.1007/BF00147625

Descartes, R. (1964-1974), Principles of Philosophy, in C. Adam \& P. Tannery (eds.) Oeuvres de Descartes, 11 vols, Paris: CNRS \& J. Vrin.

Goodman, N. (1951), The Structure of Appearance, Cambridge, MA: Harvard University Press.

GP (1875-1890), Die Philosophischen Schriften von G.W. Leibniz, 7 vol., ed. by C. I. Gerhardt, Berlin (repr. Hildesheim, 1965).

Hartz, G. A. \& Cover, J. A. (1988), 'Space and time in the Leibnizian metaphysics,' Nous, vol. 22, no. 4. https://doi.org/10.2307/2215454 
Hayes, Z. (1991), 'Bonaventure,' in H. Burkhardt \& B. Smith (eds.) Handbook of Metaphysics and Ontology, Munich, Philadelphia \& Vienna: Philosophia.

Leibniz, G. W. (1683), 'Wonders Concerning the Nature of Corporeal Substance,' in Deutsche Akademie der Wissenschaften (ed.) Gottfried Wilhelm Leibniz: Sämtliche Schriften und Briefe, Berlin: Akademie Verlag.

(1686), 'A Specimen of Discoveries of the Admirable Secrets of Nature in General,' in Deutsche Akademie der Wissenschaften (ed.) Gottfried Wilhelm Leibniz: Sämtliche Schriften und Briefe, Berlin: Akademie Verlag.

(1998), Philosophical Texts, transl. and ed. by R. S. Woolhouse \& R. Francks, Oxford: Oxford University Press.

Levey, S. (2005), 'Leibniz on precise shapes and the corporeal world,' in D. Rutherford \& J. A. Cover (eds.) Leibniz: Nature and Freedom, New York: Oxford University Press, pp. 69-94. https://doi.org/10.1093/0195143744.003.0004

(2010), 'Leibniz on time, change and corporeal substance,' in D. Garber \& S. Nadler (eds.) Oxford Studies in Early Modern Philosophy, Oxford: Clarendon Press, pp. 146-170.

Mandelbrot, B. (1977), Fractal Geometry of Nature, New York: W.H. Freeman and Company.

Müürsepp, P. (2011), 'Leibniz's critique of the Cartesian corporeal substance,' Natur un Subjekt. IX. Internationaler Leibniz-Kongress, Vorträge, 2. Teil, Hannover: GottfriedWilhelm-Leibniz-Gesellschaft, pp. 706-712.

Phemister, P. (2005), Leibniz and the Natural World. Activity, Passivity and Corporeal Substances in Leibniz's Philosophy, Dordrecht: Springer.

Rescher, N. (1979), Leibniz: An Introduction to His Philosophy, Totowa: Rowman and Littlefield.

Russell, B. (1900), A Critical Exposition of the Philosophy of Leibniz, with an Appendix of Leading Passages, Cambridge \& New York: Cambridge University Press \& Macmillan.

The Oxford Companion to Philosophy (1995), Ed. by T. Honderich, Oxford: Oxford University Press.

Vidinsky, V. (2008), 'Dynamical interpretation of Leibniz's continuum,' Kaygi: Uludag Üniversitesi Felsefe Dergisi [Uludag University Journal of Philosophy], no. 10, pp. 51-70.

Peeter Müürsepp earned his first degrees in Mathematics and Philosophy from the University of Tartu and his PhD in Philosophy from the University of Vilnius. He is Professor of Philosophy and Methodology of Science at the Tallinn University of Technology and Head of the Estonian Association for the 
Peeter Müürsepp

History and Philosophy of Science. Professor Müürsepp has been exploring the philosophy of René Thom focusing on the conception of structural stability as well as Leibniz's philosophy. More recently he has been interested in the ideas of Nicholas Maxwell, mostly concerning the difference between standard and aim-oriented empiricism. Professor Müürsepp analyses the latter topic from the perspective of practical realism. 